\title{
SISTEM PARKIR CERDAS SEDERHANA BERBASIS ARDUINO MEGA 2560 Rev3
}

\author{
Alimuddin, ST., MT. \\ Jurusan Teknik Elektro \\ Politeknik Katolik Saint Paul Sorong \\ Email:ghailan11@rocketmail.com
}

\begin{abstract}
ABSTRAK
Meningkatnya penggunaan mobil di kota Sorong tidak diseimbangkan dengan penyediaan area parkir yang memadai dan mengakibatkan banyak pengendara yang parkir di sembarang tempat. Sistem perparkiran yang ada hanya memanfaatkan area parkir dan petugas parkir yang mengawasi. Pengendara juga harus berkeliling untuk mencari tempat yang kosong apabila petugas atau pengendara tidak memperhatikan daya tampung area parkir tersebut maka pemilik kendaraan akan terpaksa harus keluar jika tidak mendapatkan tempat parkir. Untuk mengatasi hal tersebur membuat sistem parkir dengan menggunakan sistem mikrokontrol yang memudahkan pengguna kendaraan mengetahui jumlah dan letak tempat parkir yang kosong. Perancangan sistem parkir ini bertujuan kendaraan dapat mengetahui bagian lahan parkir yang tersedia yang akan diberitahukan melalui LCD (Liquid Crystal Display) dan LED (Light Emitting Diode) pada pintu masuk lahan parkir, sistem parkir ini juga dapat memisahkan kendaraan truck dan mobil biasa menggunakan PING (HC-SR04) sebagai sensor untuk mendeteksi ketinggian kendaraan pada gerbang masuk., dan juga agar memudahkan untuk mengawasi total kendaraan yang ada pada lahan parkir dengan indikator LED (Light Emitting Diode). Rancangan ini menggunakan Arduino MEGA 2560 Rev3 sebagai processor untuk mengolah data. Servo yang mengatur palang akan digerakkan sesuai deteksi pada sensor PING HC-SR04 dan LDR (Light Dependent Resistor). Saat lahan parkir penuh maka servo utama akan menutup dan mencegah kendaraan masuk lagi. Servo akan kembali terbuka saat ada lahan yang kosong. Dari hasil pengujian Arduino MEGA 2560 dapat mengatur rangkaian dengan baik serta LDR dapat mendeteksi kendaraan pada tiap area parkir, dan servo palang depan bisa mencegah mobil lain masuk saat seluruh area parkir penuh.
\end{abstract}

Keyword : Sistem Parkir, Arduino MEGA 2560, LCD, PING (HC-SR04),LDR

\section{PENDAHULUAN \\ Latar Belakang}

Meningkatnya penggunaan mobil di kota Sorong tidak diseimbangkan dengan penyediaan area parkir yang memadai dan mengakibatkan banyak pengendara yang parkir di sembarang tempat. Sistem perparkiran yang ada hanya memanfaatkan area parkir dan petugas parkir yang mengawasi.

Pengendara juga harus berkeliling untuk mencari tempat yang kosong apabila petugas atau pengendara tidak memperhatikan daya tampung area parkir tersebut maka pemilik kendaraan terpaksa harus keluar jika tidak mendapatkan tempat parkir.

Teknologi yang juga terus berkembang seiring zaman khususnya pada bidang mikrokontrol. Teknologi mikrokontroler yang sering digunakan dalam industri yang diprogram sedemikian rupa agar dapat mengontrol peralatan atau mesin secara otomatis untuk menghemat waktu dan tenaga manusia, solusi dari permasalahan perparkiran dapat dibuat dengan cara merancang sistem parkir sederhana 
dengan menggunakan Arduino MEGA 2560 sebagai mikrokontrol atau processor, LCD untuk menampilkan informasi tersedianya lahan parkir dan LED sebagai indikator untuk memberi tahu nomor area parkir yang kosong. Sistem parkir ini juga dapat menggerakkan palang secara otomatis melalui deteksi sensor ultrasonic (PING HC-SR04) agar petugas tidak perlu membukanya secara manual. Dengan sistem parkir ini para pengendara tidak perlu berkeliling untuk mencari tempat yang kosong.

\section{Rumusan Masalah}

Berdasarkan pada latar belakang yang dipaparkan, maka rumusan masalah yang diperoleh adalah bagaimana membuat sistem parkir dengan menggunakan sistem mikrokontroler yang memudahkan pengguna kendaraan mengetahui status dan nomor area parkir yang kosong.

\section{Batasan Masalah}

Dalam pembuatan sistem parkir otomatis ini, terdapat beberapa batasan masalah :

1. Perancangan menggunakan Servo Tower Pro SG90 sebagai penggerak palang dan PING (HC-SR04) sebagai sensor pendeteksi ketinggian kendaraan.

2. Status penuh dan kosongnya lahan pada rancang bangun tempat parkir ditampilkan menggunakan LCD (Liquid Crystal Display).

3. LED (Light Emitting Diode) sebagai indikator nomor area parkir yang kosong berdasarkan deteksi objek melalui LDR (Light Dependent Resistor).

\section{Tujuan dan Manfaat Pembuatan Tujuan}

Tujuan dari pembuatan Rancang Bangun Sistem Parkir Sederhana Menggunakan Arduino Mega 2560 Rev3 adalah :

1. Membuat sistem parkir menggunakan Arduino MEGA 2560.

2. Mencegah mobil lain masuk dalam area parkir setelah penuh.

\section{Manfaat}

1. Membantu pengguna kendaraan mengetahui area parkir yang tersedia.

2. Memudahkan petugas mengawasi banyaknya mobil pada lahan parkir.

\section{TINJAUAN PUSTAKA \\ Sistem Parkir}

\section{Ketentuan Umum :}

1. Parkir adalah keadaan tidak bergerak suatu kendaraan yang tidak bersifat sementara. Berhenti adalah keadaan tidak bergerak suatu kendaraan untuk sementara dengan pengemudi tidak meninggalkan kendaraan [8].

2. Fasilitas parkir adalah lokasi yang ditentukan sebagai tempat pemberhentian kendaraan yang tidak bersifat sementara untuk melakukan kegiatan pada suatu kurun waktu [8].

3. Tempat parkir di badan jalan, (on street parking) adalah fasilitas parkir yang menggunakan tepi jalan [8].

4. Fasilitas parkir di luar badan jalan (off street parking) adalah fasilitas parkir kendaraan di luar tepi jalan umum yang dibuat khusus atau penunjang kegiatan yang dapat berupa tempat parkir dan/atau gedung parkir [8].

5. Jalan adalah tempat jalan yang diperuntukan bagi lalu lintas umum.

6. Satuan ruang parkir (SRP) adalah ukuran luas efektif untuk meletakkan kendaraan (mobil penumpang, bus/truk, atau sepeda motor), 
termasuk ruang bebas dan lebar buka pintu. Untuk hal-hal tertentu bila tanpa penjelasan, SRP adalah SRP untuk mobil penumpang [8].

7. Jalur sirkulasi adalah tempat, yang digunakan untuk pergerakan kendaraan yang masuk dan keluar dari fasilitas parkir [8].

8. Jalur gang merupakan jalur antara dua deretan ruang parkir yang berdekatan [8].

9. Kawasan parkir adalah kawasan atau areal yang memanfaatkan badan jalan sebagai fasilitas parkir dan terdapat pengendalian parkir melalui pintu masuk [8].

\section{Tujuan}

Memberikan tempat istirahat kendaraan dan Menunjang kelancaran arus lalu-lintas [8].

\section{Jenis}

1. Parkir di badan jalan (on street parking) [8]
a. Pada tepi jalan tanpa pengendalian parkir
b. Pada kawasan parkir dengan pengendalian parkir

2. Parkir di luar badan jalan (off street parking) [8]

a. Fasilitas parkir untuk umum adalah tempat yang berupa gedung parkirnatau taman parkir untuk umum yang diusahakan sebagai kegiatan tersendiri.

b. Fasilitas parkir sebagai fasilitas penunjang adalah tempat yang berupa gedung parkir atau taman parkir yang disediakan untuk menunjangkegiatan pada bangunan utama.

\section{Mikrokontroller}

Mikrokontroller dapat dikatakan sebuah sistem komputer yang seluruh atau sebagian besar elemennya dikemas dalam satu chip sehingga sering disebut sebagai single chip mikrokomputer. Tidak seperti sistem komputer yang mampu menangani berbagai macam program aplikasi, mikrokontroller hanya dapat digunakan untuk suatu aplikasi saja. Perbedaan lainya yaitu pada perbandingan RAM (Rendom Acces Memory) dan ROM (Read Only Memory). Pada Mikrokontroller perbandingan antara RAM dan ROM-nya besar, sedangkan pada sistem komputer juga besar. [7].

Arduino MEGA 2560 Rev3

Arduino Mega 2560 adalah papan mikrokontroler yang berbasis pada ATmega2560. Ini memiliki 54 pin input / output digital (dimana 15 dapat digunakan sebagai output Pulse Wide Modulation), 16 input analog, 4 UART (port serial perangkat keras), osilator kristal $16 \mathrm{MHz}$, USB koneksi, colokan listrik, header ICSP, dan tombol reset, arduino ini berisi segalanya diperlukan untuk mendukung mikrokontroler, cukup hubungkan ke komputer dengan kabel USB atau diatur dengan adaptor AC ke DC atau baterai untuk memulai. Arduino Mega kompatibel dengan Shield yang dirancang untuk Arduino Duemilanove atau Diecimila [12].

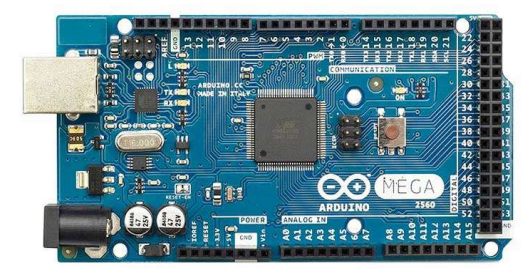

Sumber : http://ecadio.com/belajardan-mengenal-arduino-mega

Gambar 2.1 Tampilan Fisik Arduino Mega 2560 Rev3

$\begin{array}{llr}\begin{array}{l}\text { Software } \\ \text { Development } \\ \text { Arduino }\end{array} & \begin{array}{r}\text { (Integrated } \\ \text { Environment) }\end{array} \\ \end{array}$


Arduino diciptakan untuk para pemula bahkan yang tidak memiliki basic bahasa pemrograman sama sekali karena menggunakan bahasa $\mathrm{C}++$ yang telah dipermudah melalui library. Arduino menggunakan Software Processing yang digunakan untuk menulis program kedalam Arduino. Processing sendiri merupakan penggabungan antara bahasa $\mathrm{C}++$ dan Java. Software Arduino ini dapat di-install di berbagai operating system (OS) seperti: LINUX, Mac OS, Windows. Arduino tidak hanya sekedar sebuah alat pengembangan, tetapi kombinasi dari hardware, bahasa pemrograman dan Integrated Development Environment (IDE) yang canggih. IDE adalah sebuah software yang sangat berperan untuk menulis program, meng-compile menjadi kode biner dan meng-upload ke dalam memory microcontroller [7].

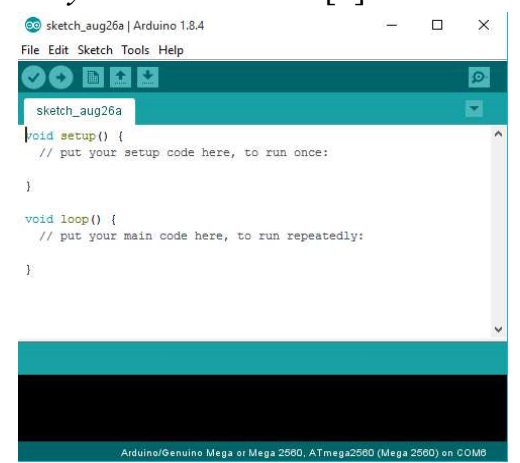

Gambar 2.2 Tampilan Software IDE Arduino

\section{Servo Tower Pro SG90}

Kecil dan ringan dengan daya output tinggi. Servo bisa berputar kirakira 180 derajat (90 di setiap arah), dan bekerja seperti jenis standar tapi lebih kecil. Anda bisa menggunakan kode servo, perangkat keras atau perpustakaan untuk mengendalikan servos ini. Bagus bagi pemula yang ingin membuat barang bergerak tanpa membangun motor controller dengan feedback \& gear box, terutama karena akan muat di tempat-tempat kecil. Muncul dengan 3 tanduk (senjata) dan perangkat keras. Posisi "0" (pulsa 1,5 ms) sedang tengah, "90" ( 2ms pulse) sedang tengah, sepanjang jalan ke kanan, "-90" (pulsa 1ms) sampai ke kiri [13].

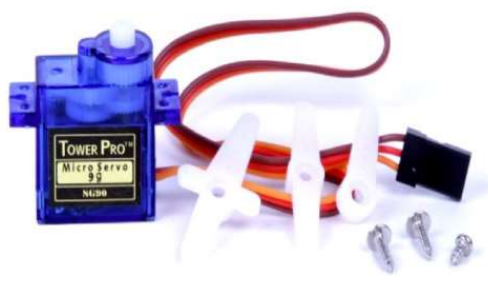

Sumber :

www.ee.ic.ac.uk/pcheung/teaching/DE1 _EE/stores/sg90_datasheet.pdf

Gambar 2.3 Bentuk Motor Servo DC
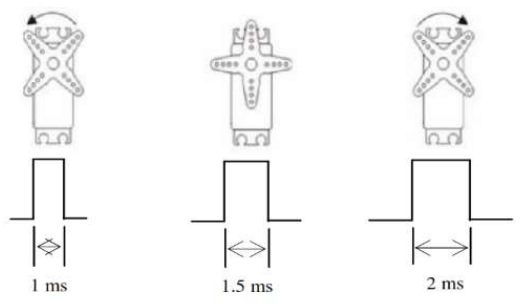

Gambar 2.4 Lebar Pulsa Yang Menentukan Putaran Pada Motor Servo

\section{Sensor Ultrasonic}

Sensor jarak ultrasonik dirancang untuk pengukuran jarak non kontak dan jenis ini terdiri dari pemancar dan penerima atau transceiver yang mampu mentransmisikan dan menerima suara ultrasonik.

\section{PING HCSR-04}

Atur rendah port Trig dan Echo saat modul menginisialisasi, tanyakan dulu setidaknya 10us pulsa level tinggi ke pin Trig (modul secara otomatis mengirimkan delapan gelombang $40 \mathrm{~K}$ persegi), dan kemudian menunggu untuk menangkap output tepi yang naik oleh port echo, pada Saat bersamaan, buka 
timer untuk memulai timing. Selanjutnya, sekali lagi ambil output tepi jatuh oleh port echo, pada saat bersamaan, baca waktu penghitung, yang merupakan waktu berjalan ultrasonik di udara. Sesuai dengan bentuknya: jarak uji $=$ (kecepatan waktu tinggi $*$ Kecepatan penyebaran ultrasonik di udara) / 2, Anda bisa menghitung jarak ke rintangan [14].

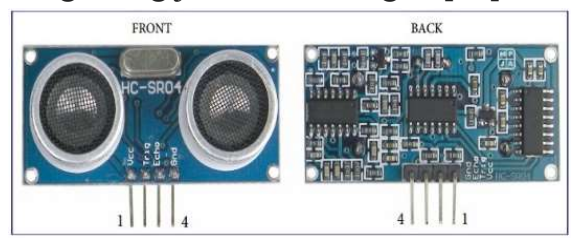

Sumber :

elecfreaks.com/estore/download/EF030 85-HC-SR04

_Ultrasonic_Module_User_Guide.pdf Gambar 2.5 PING (HC-SR04)

\section{LCD (Liquid Crystal Display) 16 x 2}

LCD adalah sebuah display dot matrix yang difungsikan untuk menampilkan tulisan berupa angka atau huruf sesuai dengan yang diinginkan (sesuai dengan program yang digunakan untuk mengontrolnya) [9].

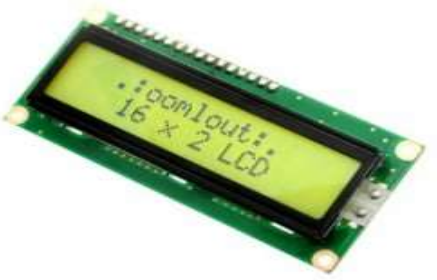

Sumber : http://elektronikadasar.web.id/lcd-liquid-cristal-display/ Gambar 2.6 LCD 2x16

\section{LED (Light Emitting Diode)}

Kebanyakan semikonduktor akan memancarkan cahaya apabila ditembaki energi. Penembakan energi ini dapat tejadi dalam bentuk elektron, cahaya atau panas. Dioda Emisi Cahaya (Light Emiting Diode) menggunakan sifat ini, dimana LED adalah dioda yang dipasang dalam wadah tembus pandang yang akan menyala/memancarkan cahaya bila dilalui arus. Dengan menggunakan unsur-unsur seperti : gelium, arsen dan posfor, maka bisa didapatkan LED yang menghasilkan cahaya merah atau cahaya tak tampak. Bila sebuah LED diberi tegangan maju, maka LED tersebut akan memancarkan cahaya karena elektron-elektron bebasnya akan bergabung kembali dengan lubang disekitar persambungan ketika melaju dari tingkat energi yang lebih tinggi ke tingkat energi yang lebih rendah [9].

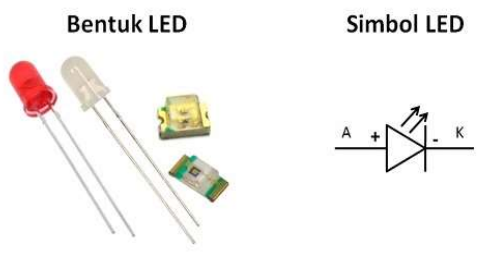

Sumber :

teknikelektronika.com/pengertian-ledlight-emitting-diode-cara-kerja/

Gambar 2.7 Bentuk dan Simbol LED Saklar

Saklar dapat memutus atau menyambung arus / tegangan listrik lemah atau komponen elektronika yang dapat digunakan untuk memindahkan aliran arus / tegangan listrik rendah dari satu konduktor ke konduktor lain. Di dunia Elektronika, saklar (switch) berfungsi sebagai pemutus dan penghubung arus listrik. Ketika kondisi saklar off (open circuit) maka arus listrik yang tadinya mengalir melalui saklar akan terputus, demikian juga sebaliknya yakni jika kondisi saklar on (close circuit) maka arus listrik akan kembali mengalir melewati saklar tersebut. 


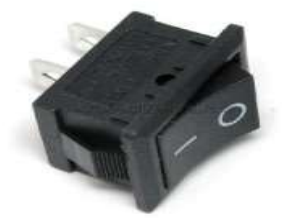

Sumber :

http://teknikelektronika.com/pengertiansaklar-listrik-cara-kerjanya/

Gambar 2.8 Bentuk Saklar

\section{LDR ( Light Dependent Resistor )}

LDR adalah suatu komponen elektronika yang memiliki hambatan yang dapat berubah sesuai perubahan intensitas cahaya. LDR adalah singkatan dari Light Dependent Resistor atau Resistor yang terpengaruh cahaya. Hambatan dari LDR akan berkurang seiring semakin besarnya intensitas cahaya yang mengenai permukaannya [9].

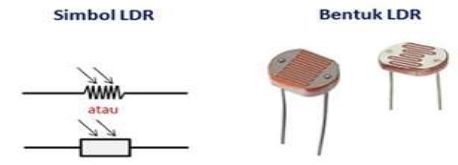

Sumber :

teknikelektronika.com/pengertian-ldrlight-dependent-resistor-caramengukur-ldr/

Gambar 2.9 Simbol dan bentuk LDR

\section{Power Supply}

Rangkaian power supply adalah suatu rangkaian yang digunakan untuk menyediakan sumber daya dalam bentuk keluaran tegangan. Tegangan yang dihasilkan disalurkan ke berbagai rangkaian lain untuk mengaktifkan rangkaian-rangkaian tersebut. Di sini diperlukan rangkaian power supply yang digunakan untuk menyediakan supply sebesar DC $+5 \mathrm{~V}$ dan DC $+9 \mathrm{~V}$ [9]. Sebuah DC Power Supply atau Adaptor pada dasarnya memiliki 4 bagian utama agar dapat menghasilkan arus DC yang stabil. Keempat bagian utama tersebut diantaranya adalah Transformer, Rectifier, Filter dan Voltage Regulator.

\section{METODOLOGI PENELITIAN DAN PERANCANGAN SISTEM \\ Metode Penelitian dan Perancangan \\ Studi Literatur}

Studi literatur digunakan untuk memperoleh informasi, dasar teori yang diperoleh dari buku dan internet sebagai studi pustaka yang mendukung pembuatan Rancang Bangun Sistem Parkir Sederhana Menggunakan Arduino Mega 2560 Rev3.

\section{Perancangan Model Alat}

Pada proses perancangan dan pembuatan Rancang Bangun Sistem Parkir Sederhana Menggunakan Arduino Mega 2560 Rev3 ini, menggunakan Sketch Up 2016, untuk menggambar desain atau model alat yang tampak seperti gambar.

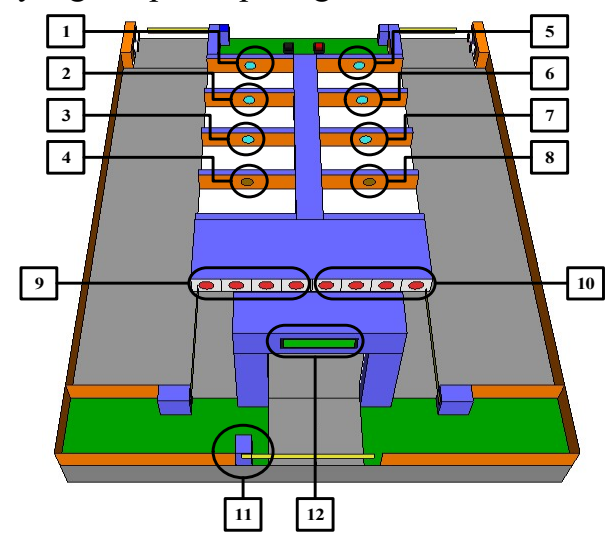

Gambar 3.1 Perancangan Sistem Parkir (Depan) 


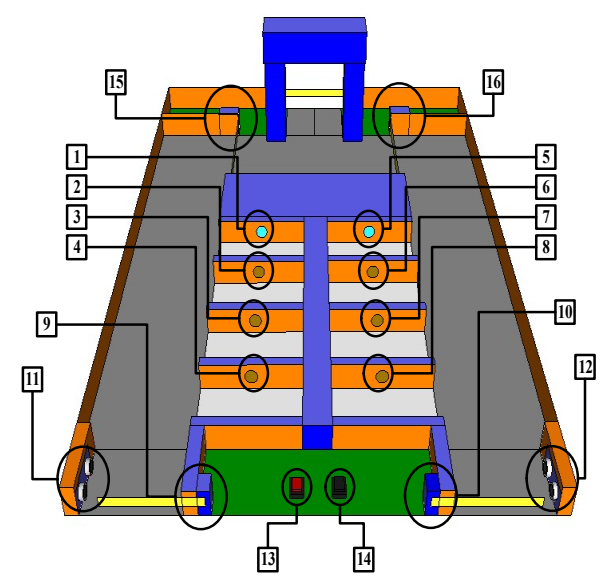

Gambar 3.2 Perancangan Sistem Parkir (Belakang)

\section{Perancangan Rangkaian Power Supply}

Rangkaian dibuat menggunakan Papan PCB berlubang $3 \mathrm{~mm}$ sebagai landasan rangkaian. Trafo CT 1 Ampere untuk menurunkan tegangan $220 \mathrm{~V}$ AC menjadi $12 \mathrm{~V}$ AC, dan 4 buah dioda IN 4002 untuk mengubah tegangan $12 \mathrm{~V}$ AC menjadi 12V DC. Kapasitor 2200 $\mu \mathrm{F} 16 \mathrm{~V}$ untuk meratakan sinyal dari dioda, IC 7805 dan IC 7809 untuk membuat tegangan $12 \mathrm{~V}$ DC menjadi $5 \mathrm{~V}$ DC dan 9V DC.

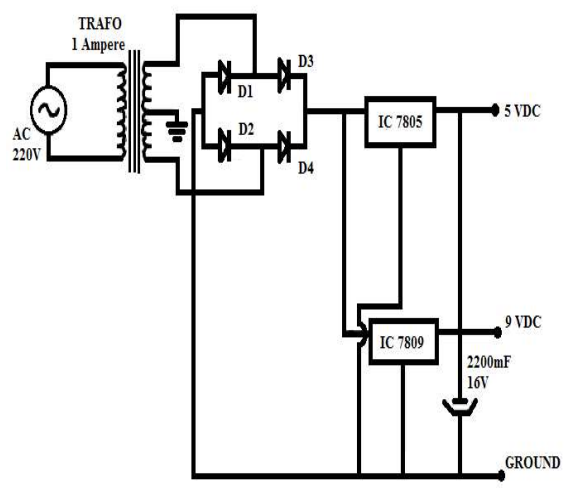

Gambar 3.3 Rangkaian Power Supply

\section{Perancangan Rangkaian \\ Mikrokontrol}

LDR1 sampai LDR8 sebagai pendeteksi pada area parkir, ketika terhalang oleh mobil maka LED indikator 1 sampai 8 (Gambar 3.1 No. 9 dan 10) akan menyala sesuai area LDR yang terhalang. PING1 berfungsi sebagai pembaca jarak tinggi mobil ketika melewati gerbang dan akan menggerakkan SERVO3 dan SERVO5. PING2 berfungsi untuk mendeteksi adanya mobil yang ingin keluar di bagian kanan area parkir dan menggerakkan SERVO2, sedangkan PING3 berfungsi untuk mendeteksi adanya mobil yang ingin keluar di bagian kiri area parkir dan menggerakkan SERVO4. SERVO1 akan menutup palang utama jika seluruh area parkir terisi dan akan terbuka kembali jika salah satu area kosong. LCD 16x2 akan menampilkan informasi status penuh atau tidaknya area parkir.

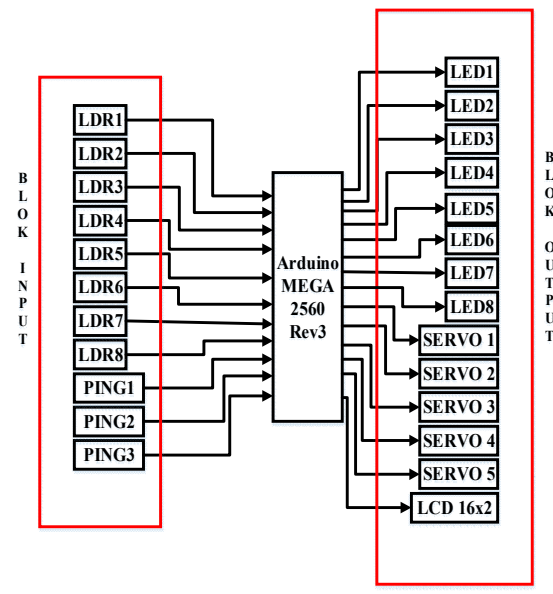

Gambar 3.4 Blok diagram perancangan mikrokontrol

\section{Prinsip Kerja Alat}

Rancang Bangun Sistem Parkir Sederhana Menggunakan Arduino Mega 2560 Rev3 ini memisahkan mobil berdasarkan tinggi mobil tersebut dan memberitahukan bagian lahan yang kosong melalui indikator LED (Light Emitting Diode) dan LCD (Liquid Crystal Display). Servo yang mengatur 
palang akan digerakkan sesuai deteksi pada sensor PING HC-SR04 dan LDR (Light Dependent Resistor). Saat lahan parkir penuh maka servo yang mengatur palang masuk akan menutup dan mencegah kendaraan masuk lagi. Servo akan kembali terbuka saat ada lahan yang kosong

\section{Perencanaan Kerja}

Dalam pembuatan Rancang Bangun Sistem Parkir Sederhana Menggunakan Arduino Mega 2560 Rev3, hal-hal yang akan dilakukan adalah :

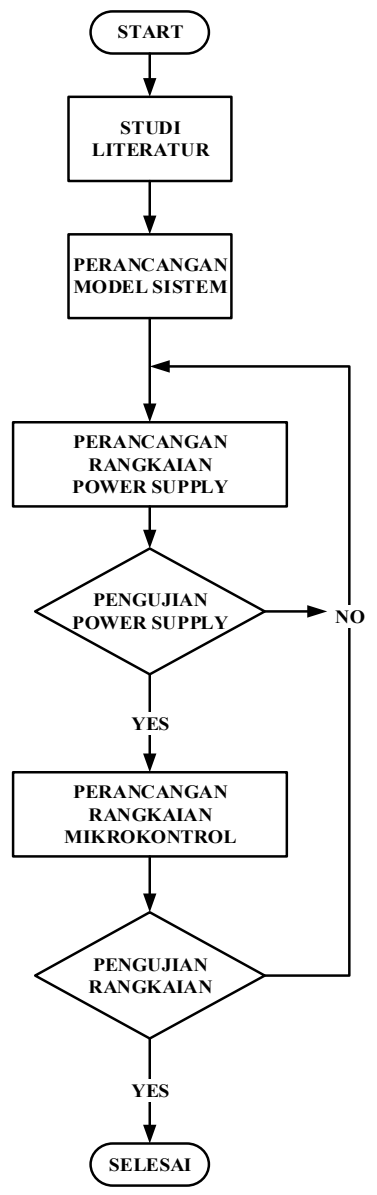

Gambar 3.5 Alur Perencanaan

Pengujian Sistem Yang Dilaksanakan Pengujian Perangkat Keras

Pengujian Port Arduino

Pengujian Rangkaian Adaptor
Pengujian Sensor Ping

Pengujian Rangkaian LCD 16x2

Pengujian Servo

Pengujian LDR

Pengujian Perangkat Lunak

$>$ Pengujian software editor arduino dengan pemograman

$>$ Pengujian pentransferan pemograman pada Arduino

\section{PENGUJIAN ALAT DAN \\ PEMBAHASAN \\ Pengujian Program IDE pada Arduino MEGA 2560 Rev3}

Program ini akan berkomunikasi dari komputer ke modul kit Arduino MEGA 2560 Rev3 dengan berbagai jenis tampilan program yang dapat di transfer ke Arduino MEGA 2560 Rev3.

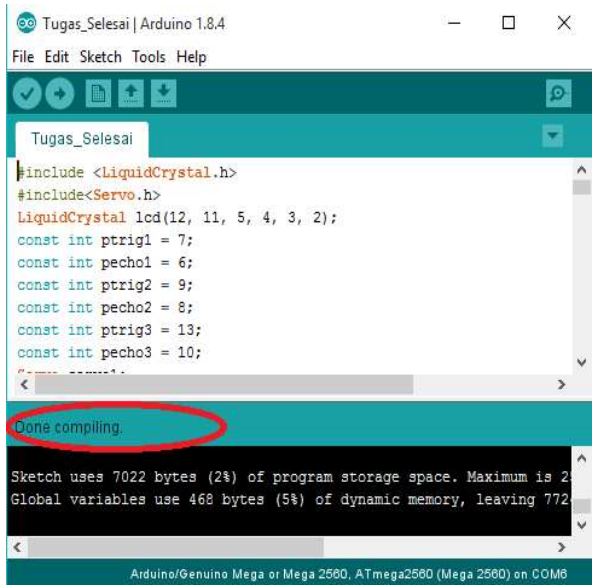

Gambar Tampilan Sketch Arduino Saat Program Valid

Tampilan dari gambar diatas merupakan tampilan pengujian program yang terjadi jika ingin mengetahui apabila program yang di buat itu valid atau invalid klik menu $\checkmark$. Apabila tampilan dari pengujian program yang di uji, dibagian bawah dari sketch pemrograman bertuliskan Done 
Compilling seperti pada gambar 4.5 diatas, berarti tidak ada kesalahan yang terjadi pada saat program, dan bisa langsung diupload dengan menu $\rightarrow$ ke Arduino Mega 2560 Rev3.

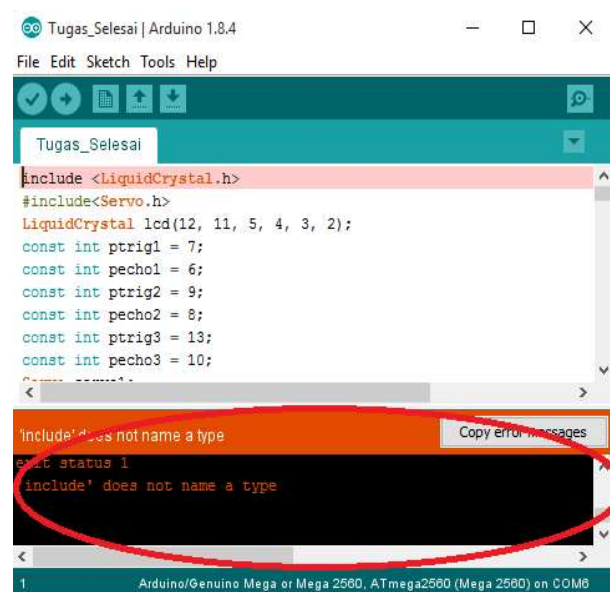

Gambar Tampilan Sketch Arduino Saat Program Invalid

Namun jika pemrograman terjadi kesalahan atau invalid, pada bagian bawah dari sketch pemrograman akan tampil komentar berwarna orange seperti pada gambar 4.6 diatas, dan program tidak bisa diupload ke arduino mega2560 Rev3. Periksa kembali program yang dibuat apabila ada penulisan yang tidak sesuai dengan bahasa pada software atau program sampai compile berhasil dan bisa di upload.

\section{Pengujian Power Supply}

Rangkaian adaptor yang dibuat berfungsi untuk memberikan tegangan pada komponen yang akan digunakan dalam sistem parkir. Output dari pada rangkaian catu daya ini adalah sebesar 12VDC dan distabilkan IC Regulator 7805 dan 7809 sehingga tegangannya $5 \mathrm{~V}$ dan $9 \mathrm{~V}$.

\begin{tabular}{cccc}
\hline Pengujian & Hasil Pengukuran & $\begin{array}{c}\text { Hasil } \\
\text { Sebenarnya }\end{array}$ & \% error \\
\hline Input pada Trafo & $226 \mathrm{VAC}$ & $220 \mathrm{VAC}$ & 2.72 \\
$\begin{array}{c}\text { Output dari Trafo } \\
\text { Output Adaptor } \\
5 \mathrm{~V}\end{array}$ & $12 \mathrm{VAC}$ & $12 \mathrm{VAC}$ & 0 \\
$\begin{array}{c}\text { Output Adaptor } \\
\text { 9V }\end{array}$ & $9.96 \mathrm{VDC}$ & $5 \mathrm{VDC}$ & 1 \\
\hline
\end{tabular}

Pengujian Port Pada Arduino MEGA 2560 Rev3

Pengujian Port I/O Arduino MEGA 2560 Rev3 dilakukan dengan cara mengukur tegangan keluaran pada portnya. Port yang diberi logika HIGH akan mengeluarkan tegangan $\pm 5 \mathrm{VDC}$ yang akan memberi signal tertentu pada komponen agar bekerja sesuai dengan program yang diberikan.

\section{Hasil Pengujian Port I/O Pada}

Arduino MEGA 2560 Rev3

\begin{tabular}{cccc}
\hline $\begin{array}{c}\text { Pengujia } \\
\mathbf{n}\end{array}$ & $\begin{array}{c}\text { Hasil } \\
\text { Pengukuran }\end{array}$ & $\begin{array}{c}\text { Hasil } \\
\text { Sebenarnya }\end{array}$ & $\begin{array}{c}\% \\
\text { error }\end{array}$ \\
\hline Port 2 & 4.93 VDC & 5 VDC & 1.4 \\
Port 22 & 4.93 VDC & 5 VDC & 1.4 \\
\hline
\end{tabular}

Pengujian Sensor PING HC-SR04

Pengujian pada HC-SR04

Menggunakan Arduino MEGA 2560

dan Software Serial Monitor pada Software Arduino IDE. Listing program yang digunakan adalah sebagai berikut :

\section{Hasil Pengujian PING}

\begin{tabular}{cccc}
\hline Pengujian & $\begin{array}{c}\text { Hasil } \\
\text { Serial } \\
\text { Monitor }\end{array}$ & $\begin{array}{c}\text { Hasil } \\
\text { Sebenarnya }\end{array}$ & $\begin{array}{c}\text { \% } \\
\text { error }\end{array}$ \\
\hline PING 1 & $7 \mathrm{~cm}$ & $7.6 \mathrm{~cm}$ & 7.8 \\
PING 2 & $9 \mathrm{~cm}$ & $8.5 \mathrm{~cm}$ & 5.8 \\
PING 3 & $7 \mathrm{~cm}$ & $6.8 \mathrm{~cm}$ & 2.8 \\
\hline
\end{tabular}

\section{Pengujian Sensor LDR}

Pengujian dilakuan dengan mengukur langsung tahanan pada kaki LDR yang terkena resistor $330 \mathrm{ohm}$. Pengujian ini juga dilakukan dengan LDR disambungkan ke port analog A1 - 
A8 pada Arduino dan cahaya yang akan diterima diatur dengan LED. Hasil tahanan LDR akan ditampilkan pada serial monitor aplikasi arduino IDE. Hasil pada serial monitor akan dihitung untuk mendapatkan nilai tegangan dan dibandingkan dengan pengukuran langsung.

\section{Hasil Pengujian LDR}

\begin{tabular}{|c|c|c|}
\hline \multirow{2}{*}{ Pengujian } & \multicolumn{2}{|c|}{$\begin{array}{c}\text { Pengukuran } \\
\text { Sebenarnya }\end{array}$} \\
\hline & $\begin{array}{l}\text { Terkena } \\
\text { Cahaya }\end{array}$ & $\begin{array}{l}\text { Cahaya } \\
\text { Terhalang }\end{array}$ \\
\hline LDR 1 & $4.62 \mathrm{~V}$ & $4.93 \mathrm{~V}$ \\
\hline LDR 2 & $4.45 \mathrm{~V}$ & $4.94 \mathrm{~V}$ \\
\hline LDR 3 & $4.46 \mathrm{~V}$ & $4.90 \mathrm{~V}$ \\
\hline LDR 4 & $4.51 \mathrm{~V}$ & $4.90 \mathrm{~V}$ \\
\hline LDR 5 & $4.35 \mathrm{~V}$ & $4.83 \mathrm{~V}$ \\
\hline LDR 6 & $4.50 \mathrm{~V}$ & $4.91 \mathrm{~V}$ \\
\hline LDR 7 & $4.45 \mathrm{~V}$ & $4.93 \mathrm{~V}$ \\
\hline LDR 8 & $4.40 \mathrm{~V}$ & $4.87 \mathrm{~V}$ \\
\hline
\end{tabular}

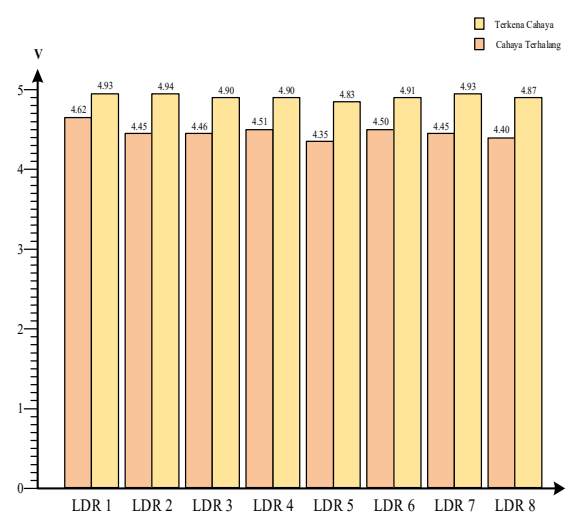

Gambar Grafik Pengukuran Langsung LDR

\begin{tabular}{ccc}
\hline Pengujian & \multicolumn{2}{c}{ Serial Monitor } \\
& $\begin{array}{c}\text { Terkena } \\
\text { Cahaya }\end{array}$ & $\begin{array}{c}\text { Cahaya } \\
\text { Terhalang }\end{array}$ \\
\hline LDR 1 & 936 & 997 \\
LDR 2 & 904 & 998 \\
LDR 3 & 904 & 989
\end{tabular}

\begin{tabular}{|c|c|c|}
\hline LDR 4 & 918 & 993 \\
\hline LDR 5 & 882 & 966 \\
\hline LDR 6 & 912 & 994 \\
\hline LDR 7 & 905 & 992 \\
\hline LDR 8 & 893 & 988 \\
\hline
\end{tabular}

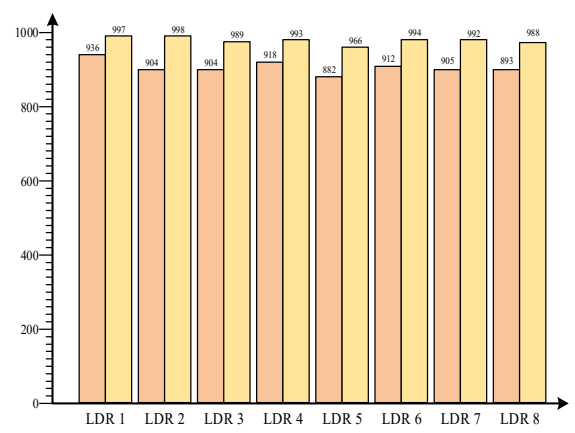

Gambar Grafik Pembacaan Serial Monitor Terhadap LDR

Menghitung nilai tegangan dengan hasil dari serial monitor :

$\mathrm{V}_{\mathrm{LDR}}=($ Pembacaan Serial Monitor $\times 5)$ $/ 1023$

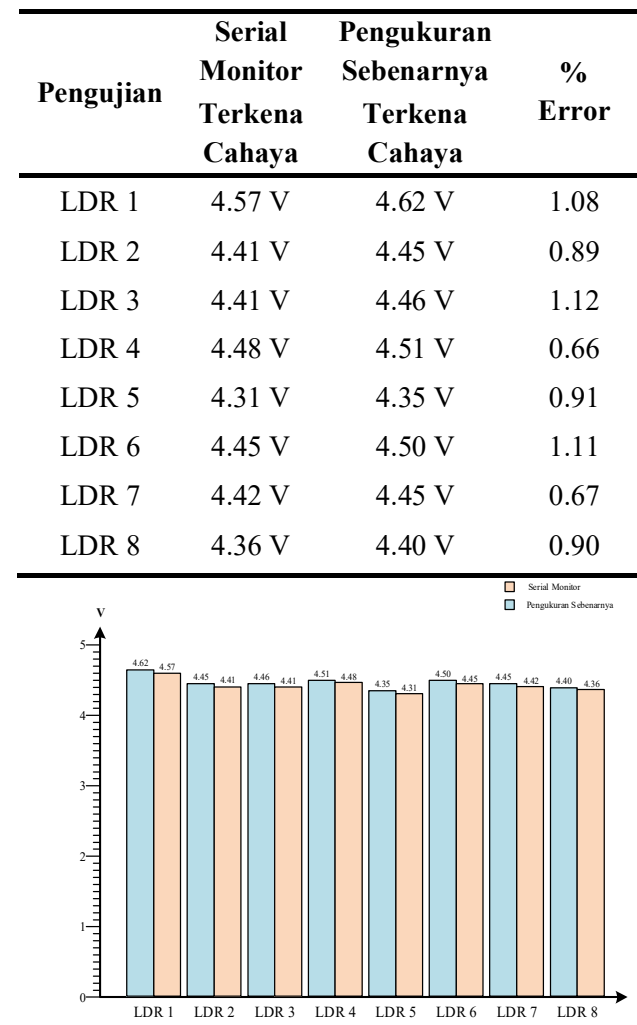


Gambar Perbandingan Pengukuran dan Serial Monitor Saat Terkena Cahaya

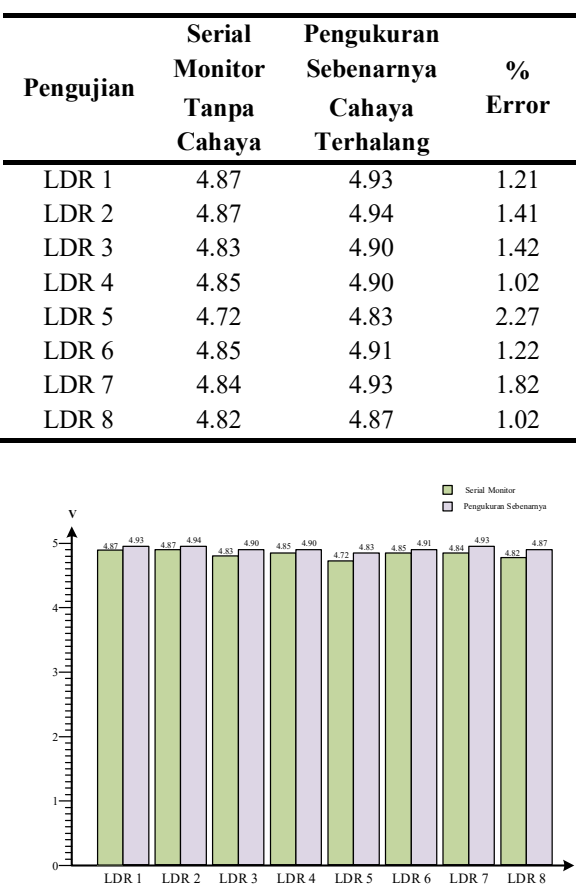

Gambar Perbandingan Pengukuran \&

Serial Monitor Saat Cahaya Terhalang

Pengujian Tampilan LCD

Pengujian LCD 16x2 dilakukan dengan tujuan untuk mendapatkan parameter berupa tampilan karakter pada LCD sesuai dengan keinginan. Pengujian dilakukan dengan memprogram karakter atau tulisan yang ingin ditampilkan pada LCD. Contoh listing program yang dipakai sebagai berikut :

\#include <LiquidCrystal.h>

LiquidCrystal lcd(12, 11, 5, 4, 3, 2);

void setup()

\{lcd.begin $(16,2) ;\}$

void loop()

\{lcd.print("Sistem Parkir");

lcd.setCursor $(0,1)$;

lcd.print("Zulfikar A Fakih");

delay(10000);
Hasil Tampilan LCD sebagai berikut :

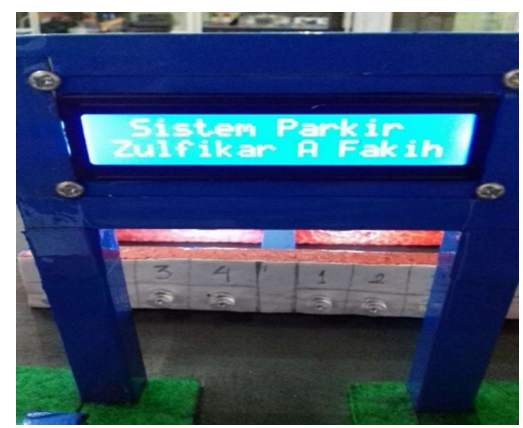

Gambar Tampilan Listing Program

\section{Pengujian Servo}

Pengujian menggunakan servo dilakukan pengujian terhadap rangkaian dengan cara mengukur tegangan pada output signal pada servo tersebut.

Hasil Pengujian Rangkaian Servo

\begin{tabular}{cc}
\hline Pengujian & Hasil Pengukuran \\
\hline $\begin{array}{c}\text { Tegangan output signal } 0^{\circ} \\
\text { Tegangan output signal } \\
90^{\circ}\end{array}$ & $0,13 \mathrm{VDC}$ \\
$\begin{array}{c}\text { Tegangan output signal } \\
180^{\circ}\end{array}$ & $0,37 \mathrm{VDC}$ \\
\hline
\end{tabular}

\section{PENUTUP}

\section{Kesimpulan}

Adapun kesimpulan yang dapat diambil dari hasil pengujian "Sistem Parkir Sederhana Menggunakan Arduino Mega 2560 Rev3" adalah sebagai berikut:

1) Mobil akan dipisahkan sesuai ketinggian yang diatur pada program dan juga servo yang akan terbuka setelah melewati gerbang awal tergantung dari deteksi tinggi mobil tersebut.

2) LDR digunakan sebagai pendeteksi adanya mobil/truck pada lahan parkir informasi ada dan penuh ditunjukan lampu indikator dan LCD.

3) Saat kendaraan pada semua lahan parkir terisi maka servo 1 akan 
menutup untuk mencegah mobil masuk agar tidak melebihi kapasitas tampung lahan parkir.

4) Persentase error pada perbandingan pengukuran langsung dan pembacaan serial monitor pada pengujian LDR tidak terlalu besar.

\section{Saran}

1) Sistem parkir dapat dikembangkan dengan menampilkan sisa lahan parkir pada LCD dengan menggunakan sensor deteksi yang berbeda.

2) Penggunaan PING sebagai pendeteksi jarak tinggi mobil membutuhkan kalibrasi pada program sebelum digunakan, agar jarak hitung PING sesuai dengan asli.

\section{DAFTAR PUSTAKA}

[1]Dian, Artanto.2012."Interaksi Arduino dan Lab VIEW".Jakarta : PT Alex Media Komputindo

[2]Brian, Evans.2011."Beginning Arduino Programming ". 233 Spring Street, 6th Floor, New York, NY 10013.Springer Science+Business Media, LLC.

[3]Donald, Wilcher.2012."Learn Electronics With Arduino". 233 Spring Street, 6th Floor, New York, NY 10013.Springer

Science+Business Media, LLC.

[4] A. M. Haidar, C. Benachaiba \& M. Zahir. 2013. "Software Interfacing Of Servo Motor With Microcontroller “. Australia. Journal of Electrical Systems, vol.9, (1) pp. 84-99

[5] Michal Kelemen, Ivan Virgala, Tatiana Kelemenová, Lubica Miková, Peter Frankovský,Tomáš Lipták, and Milan Lörinc. 2015. "Distance Measurement via Using of Ultrasonic Sensor". Kosice, Slovak
Republic. Journal of Automation and Control, 2015, Vol. 3, No. 3, 71-74

[6]Maik, Schmidt. 2011. " Arduino A Quick-Start Guide" North Carolina Dallas, Texas. The Pragmatic Bookshelf Raleigh

[7]Jauhari Arifin, Leni Natalia Zulita, Hermawansyah. 2016. " Perancangan Murottal Otomatis Menggunakan Mikrokontroller Arduino MEGA 2560".Bengkulu.Jurnal Media Infotama Vol. 12 No. 1

[8]Departemen Perhubungan.1996. Pedoman Teknis Penyelenggaraan Fasilitas Parkir. Jakarta. Direktur Jenderal Perhubungan Darat

[9]Ruri Hartika Zain.2013. "Sistem Keamanan Ruangan Menggunakan Sensor Passive Infra Red (PiR) DilengkapI Kontrol Penerangan Pada Ruangan Berbasis Mikrokontroler ATmega8535 dan Real Time Clock DS1307." JURNAL TEKNOLOGI INFORMASI \& PENDIDIKAN VOL. 6 NO. 1

[10] Dickson Kho Pengertian Saklar Listrik dan Cara Kerjanya teknikelektronika.com/pengertiansaklar-listrik-cara-kerjanyal. Akses 10:35 26 Agustus 2017

[11] Dickson Kho Prinsip Kerja DC Power Supply (Adaptor) teknikelektronika.com/prinsip-kerjadc-power-supply-adaptor/ Akses 10:38 26 Agustus 2017

[12] Arduino Datasheet. www.mantech.co.za/datasheets/prod ucts/A000047.pdf

[13] ServoSG90Datasheet.www.ee.ic.ac.u $k / p$ cheung/teaching/DE1_EE/stores/s g90datasheet.pdf

[14] PING-HCSR04.elecfreaks.com/ estore/download/EF03085-HC-SR04 _Ultrasonic_Module_User_Guide.pdf 